\title{
A Low-Cost Visible Light Communications System Based on Organic Photodetection for Transmitting Images ${ }^{t}$
}

\author{
Pablo Corral *D, Fernando Rodríguez-Mas $\mathbb{D}^{\text {, }}$, José Luis Alonso, Juan Carlos Ferrer and Susana Fernández de Ávila \\ Communications Engineering Department, Universidad Miguel Hernández, Av. Universidad, s/n, Ed. Innova, \\ 03202 Elche, Spain; fernando.rodriguezm@umh.es (F.R.-M.); j.l.alonso@umh.es (J.L.A.); jc.ferrer@umh.es (J.C.F.); \\ s.fdezavila@umh.es (S.F.d.Á.) \\ * Correspondence: pcorral@umh.es \\ † Presented at the 8th International Symposium on Sensor Science, 17-28 May 2021; Available online: \\ https://i3s2021dresden.sciforum.net/.
}

check for

updates

Citation: Corral, P.; Rodríguez-Mas, F.; Alonso, J.L.; Ferrer, J.C.; Fernández de Ávila, S. A Low-Cost Visible Light Communications System Based on Organic Photodetection for Transmitting Images. Eng. Proc. 2021, 6, 85. https://doi.org/10.3390/ I3S2021Dresden-10116

Academic Editors: Gianaurelio Cuniberti and Larysa Baraban

Published: 17 May 2021

Publisher's Note: MDPI stays neutral with regard to jurisdictional claims in published maps and institutional affiliations.

Copyright: (C) 2021 by the authors. Licensee MDPI, Basel, Switzerland. This article is an open access article distributed under the terms and conditions of the Creative Commons Attribution (CC BY) license (https:/ / creativecommons.org/licenses/by/ $4.0 /)$.
Abstract: In Visible Light Communication (VLC) Systems, data are transmitted by modulating light from an illumination source, that could be an ordinary lamp or light-emitting diodes (LEDs). Photovoltaic cells based on massive heterojunctions of semiconductor polymers have focused the attention of researchers due to several potential advantages over their inorganic counterparts, such as simplicity, low cost and the ability to process large area devices even on flexible substrates. In this paper, we use commercial LEDs in transmission and organic photodetectors (OPD) based on poly(3-hexylthiophene) (P3HT) and a phenyl-C61-butyric acid methyl ester (PCBM) blend used as active layer in reception. We have fabricated and characterized the I-V curve and the Bit Error Rate (BER) response of the OPD using low cost processing techniques and we have used an Atmel 8-bit microcontroller in order to control the electronics to transmit and modulate the signal. Finally, in this work, we have developed and characterized organic photodetectors in a low cost visible light communications system capable of transmitting an image file in real-time, as a proof of concept that is cost effective, since the whole system was implemented using low cost components. You can find more information in the supplementary materials.

Keywords: visible light communications; organic photodetector; P3HT:PCBM; IEEE 802.15.7

Supplementary Materials: The poster presentation and video are available online at https:/ /www. mdpi.com/article/10.3390/I3S2021Dresden-10116/s1.

Author Contributions: Conceptualization, P.C.; software, P.C.; formal analysis, P.C.; investigation, P.C., F.R.-M. and J.L.A.; data curation, P.C. and F.R.-M.; writing-review and editing, P.C., F.R.-M., J.L.A., J.C.F. and S.F.d.Á. All authors have read and agreed to the published version of the manuscript.

Funding: This research was funded by the Conselleria d'Educació, Investigació, Cultura i Esport from Generalitat Valenciana under the project GV/2017/012 and AICO/2017/148.

Institutional Review Board Statement: Not applicable.

Informed Consent Statement: Not aplicable.

Acknowledgments: The authors thanks David Valiente and Abraham Ruiz for providing comprehensive training on the various measurement techniques.

Conflicts of Interest: The authors declare no conflict of interest. 